\title{
Traditional Chinese medicine, Fuzheng Kang-Ai decoction, inhibits metastasis of lung cancer cells through the STAT3/MMP9 pathway
}

\author{
LONGMEI LI ${ }^{1-3^{*}}$, SUMEI WANG ${ }^{2 *}$, XIAOBIN YANG ${ }^{2}$, SHUNQIN LONG ${ }^{2}$, \\ SHUJING XIAO ${ }^{2}$, WANYIN WU ${ }^{2}$ and SWEI SUNNY HANN ${ }^{1}$ \\ ${ }^{1}$ Laboratory of Tumor Biology and Targeted Therapies of TCM; ${ }^{2}$ Department of Medical Oncology, \\ Guangdong Provincial Hospital of Chinese Medicine; ${ }^{3}$ Guangzhou University of Chinese Medicine, \\ Guangzhou, Guangdong 510120, P.R. China
}

Received July 8, 2016; Accepted April 28, 2017

DOI: $10.3892 / \mathrm{mmr} .2017 .6905$

\begin{abstract}
Lung cancer is a leading cause of cancer-associated mortality worldwide, including in developing countries such as China. Traditional Chinese medicine may provide a novel insight for the treatment of patients with lung cancer. The present study aimed to uncover the mechanism by which the Chinese herbal medicine, Fuzheng Kang-Ai (FZKA), functions on lung cancer cell metastasis. The results demonstrated that treatment with FZKA markedly inhibited cell viability, migration and invasion of lung cancer cells, as determined by cell viability and Transwell assays. Notably, the activity and expression of matrix metalloproteinase 9 (MMP9) was significantly inhibited by FZKA treatment on lung cancer cells, as determined by an MMP9 activity assay and western blot analysis. Furthermore, FZKA markedly inhibited epithelial-mesenchymal transition (EMT) of lung cancer cells by inhibiting the expression of the mesenchymal markers $\mathrm{N}$-cadherin and vimentin. In addition, activation of the oncoprotein signal transducer and activator of transcription 3 (STAT3) was suppressed following treatment with FZKA. Conversely, overexpression of STAT3 was able to rescue
\end{abstract}

Correspondence to: Professor Swei Sunny Hann, Laboratory of Tumor Biology and Targeted Therapies of TCM, Guangdong Provincial Hospital of Chinese Medicine, 55 Inner Ring West Road, Higher Education Mega Center, Guangzhou, Guangdong 510120, P.R. China

E-mail: hann2012@outlook.com

Professor Wanyin Wu, Department of Medical Oncology, Guangdong Provincial Hospital of Chinese Medicine, 111 Dade Road, Guangzhou, Guangdong 510120, P.R. China

E-mail:wwanyin@126.com

${ }^{*}$ Contributed equally

Key words: Fuzheng Kang-Ai decoction, lung cancer, STAT3/MMP9 pathway, epithelial-mesenchymal transition
MMP9 activity following FZKA treatment. The present study indicated that FZKA may inhibit lung cancer metastasis via the STAT3/MMP9 pathway and EMT, suggesting that FZKA may serve as a novel promising therapeutic strategy for the treatment of patients with late stage lung cancer.

\section{Introduction}

Lung cancer is a leading cause of cancer-associated mortality worldwide (1). It is the most common fatal cancer in males and females, and accounts for 29 and $26 \%$ of all male and female cancer-associated mortalities worldwide, respectively (2). In China, lung cancer is the most frequently diagnosed cancer in males $(22.14 \%)$, and is the leading cause of cancer-associated mortality in males (27.21\%) and females (21.91\%) (3). Despite advances in combination chemotherapy and surgical techniques, the prognosis of non-small cell lung cancer (NSCLC) remains poor; the 5-year survival rate for all stages and subtypes combined remains as low as $11 \%$ (4). Metastasis is the predominant cause of mortality in patients with lung cancer; $\sim 90 \%$ of patients succumb to metastatic cancer (5). The metastatic process is initiated by dissemination of clonal cells from the primary tumor site, which invade the extracellular matrix (ECM) and surrounding stroma (6).

The matrix metalloproteinase (MMP) family members are involved in degradation of the ECM during normal physiological processes, including embryonic development and tissue remodeling, as well as in disease processes, including tumor metastasis (7). MMP9 is a member of the ECM (8-10). Overexpression of MMP9 has been reported to facilitate metastatic spread of various cancer cells, including lung cancer cells. A recent study demonstrated that MMP9 expression is positively correlated with lung cancer malignancy (11), and suggested that MMP9 is an important factor in the process of lung cancer metastasis. Furthermore, the process of epithelial-mesenchymal transition (EMT) is known to serve an important role in metastasis formation (12). The series of EMT events is predominantly activated in cancer cells acquiring invasive and metastatic properties (13); MMP9 and EMT are critical in the processes associated with cancer 
metastasis. Signal transducer and activator of transcription 3 (STAT3) is an oncogenic transcription factor known to be involved in cancer cell proliferation and metastasis (14). In numerous types of cancer, STAT3 is constitutively active, leading to continued expression of target genes that promote cell proliferation, survival and invasion. The role of STAT3 in tumorigenesis and cancer cell invasion has been well established in a wide range of human cancers, including lung cancer (15). When activated by upstream signaling pathways, including epidermal growth factor and the interleukin-6/Janus kinase pathway, STAT3 is phosphorylated and then forms homodimers or heterodimers with other members of the STAT family. Subsequently, the activated STAT3 complex translocates into the nucleus to initiate transcription of STAT3 target genes, including MMP9 (16).

Fuzheng Kang-Ai (FZKA) decoction, initially prescribed by $\mathrm{Dr}$. Wanyin $\mathrm{Wu}$ (17), has been used to treat patients with NSCLC at the Guangdong Provincial Hospital of Traditional Chinese Medicine (Guangzhou, China) for a decade, and has been shown to exert a positive impact on patient health. Our previous study demonstrated that the efficacy of a combination of gefitinib plus FZKA exhibited better outcome compared with gefitinib alone (17). In addition, FZKA could enhance the disease control rate, and prolong the progression-free survival (PFS) and median survival time (MST) in patients with NSCLC $(18,19)$. Furthermore, our recent study reported that FZKA inhibited lung cancer cell growth through AMP-activated protein kinase $\alpha$-mediated induction, and an interplay between insulin-like growth factor-binding protein 1 and forkhead box O3a, indicating its therapeutic effect on lung cancer (20). Metastasis is the predominant cause of mortality in patients with lung cancer; however, the mechanism by which FZKA affects lung cancer metastasis remains to be elucidated. The present study identified the inhibitory effects of FZKA on lung cancer cell invasion and migration. In addition, the probable mechanisms by which FZKA inhibited lung cancer cell metastasis were examined, which may provide evidence to support the clinical usage of FZKA decoction to treat patients with NSCLC.

\section{Materials and methods}

Cells. Human A549 NSCLC cells were obtained from the Cell Line Bank at the Laboratory Animal Center of Sun Yat-sen University (Guangzhou, China). PC9 and H1650 cells were obtained from the Chinese Academy of Sciences Cell Bank of Type Culture Collection (Shanghai, China). All cells were cultured in RPMI-1640 medium (Gibco; Thermo Fisher Scientific, Inc., Waltham, MA, USA) supplemented with 10\% FBS (Gibco; Thermo Fisher Scientific, Inc.) and $0.5 \%$ penicillin-streptomycin sulfate, and incubated at $37^{\circ} \mathrm{C}$ with $5 \% \mathrm{CO}_{2}$. Cells were counted using a Countstar automated cell counter (Inno-Alliance Biotech, Inc., Wilmington, DE, USA).

Chemicals. Monoclonal antibodies against total STAT3 (cat no. 8232), phosphorylated (p)-STAT3 (cat. no. 4093), vimentin (cat. no. 12826), N-cadherin (cat. no. 13116) and MMP9 (cat. no. 13667) were purchased from Cell Signaling Technology, Inc. (Danvers, MA, USA). Lipofectamine 3000 reagent was purchased from Invitrogen (Thermo Fisher Scientific, Inc.). The control (pCMV6-AC) and STAT3 overexpression (pCMV6-AC-STAT3) vectors were obtained from OriGene Technologies, Inc. (Rockville, MD, USA).

FZKA decoction. FZKA decoction is a Chinese herbal medicine that has been used to treat NSCLC at the Guangdong Provincial Hospital of Traditional Chinese Medicine for $>10$ years. It consists of Taizishen, $30 \mathrm{~g}$; Atractylodes macrocephala Koidz. (Baizhu), 15 g; Astragalus membranaceus (Fisch.) Bge. (Huangqi), $30 \mathrm{~g}$; Oldenlandia diffusa (Willd.) Roxb. (Baihuasheshecao), 30 g; Solanum nigrum L. (Longkui), 30 g; Salvia chinensis Benth (Shi-jianchuan), 30 g; Cremastra appendiculata (D. Don) Makino (Shancigu), $30 \mathrm{~g}$; Coix lachrymal-jobi L. (Yiyiren), $30 \mathrm{~g}$; Akebia quinata (Thunb.) Decne (Bayuezha), 30 g; Rubus parviflolius L. (Shepaole), $30 \mathrm{~g}$; Curcuma kwangsiensis S.G. Lee et C.F. Liang (Ezhu), $15 \mathrm{~g}$; and Glycyrrhiza uralensis Fisch. (Gancao), $10 \mathrm{~g}$ (19). All of the components were soaked together for $30 \mathrm{~min}$ prior to decoction. The concentrated liquid was finally spray dried into particles by Guangdong One Pharmaceutical Co., Ltd (Guangzhou, Guangdong, China). The FZKA particles were dissolved in RPMI-1640 and filtered using $0.22 \mu \mathrm{m}$ filters prior to use. The $\mathrm{pH}$ value of the cultured cells in media was adjusted to 7.2-7.4 following FZKA addition.

Cell viability assay. Cells were seeded in 6-well plates at a density of $3 \times 10^{5}$ cells/well. After $24 \mathrm{~h}$ of culture, cells were treated with FZKA $(0,1,2$ and $3 \mathrm{mg} / \mathrm{ml})$ and were incubated at $37^{\circ} \mathrm{C}$ for $24 \mathrm{~h} ; 0 \mathrm{mg} / \mathrm{ml} \mathrm{FZKA}$ cultured cells were used as the untreated control cells. Subsequently, cells were collected by trypsinization and stained with trypan blue at a concentration of 1:1. The cells were resuspended and were then counted using a Countstar automated cell counter. Cell viability was expressed as a percentage of untreated cells. Data were taken from an average of three independent experiments.

Wound-healing assay. Wound-healing assay was performed to determine the migratory ability of cells. The cells were cultured $\left(4 \times 10^{5}\right)$ in 6 -well plates, and incubated until the cell density reached $90 \%$. Cell monolayers were wounded by scratching with a $200-\mu 1$ pipette tip, after which the plates were washed twice with PBS to remove detached cells, and were incubated in RPMI-1640 supplemented with 2\% FBS containing FZKA $(0,1$ and $2 \mathrm{mg} / \mathrm{ml})$. After 12 or $24 \mathrm{~h}$ at $37^{\circ} \mathrm{C}$, the medium was replaced with PBS and washed twice. The wound gap was observed and images were captured using a fluorescence microscope (Olympus IX71; Olympus Corporation, Tokyo, Japan; magnification, $\mathrm{x} 40$ ). The distance of the scratch was measured using ImageJ software (version 1.48; National Institutes of Health, Bethesda, MD, USA). The results were obtained from three independent experiments.

Transwell assay. A Transwell plate (Corning Incorporation, Corning, NY, USA; diameter, $10 \mathrm{~mm} ; 8 \mu \mathrm{m}$ pore polycarbonate membrane) was used to detect the migratory and invasive potential of the cells. In the invasion assay, prior to experimentation, Matrigel (BD Bioscience, San Jose, CA, USA) was diluted 8-fold using PBS and was injected into the upper 
chamber. In the migration assay, this step was omitted. To the lower chamber, $500 \mu 1$ cell culture medium supplemented with $30 \%$ FBS was added. Subsequently, cells were diluted to $0.5 \times 10^{6} / \mathrm{ml}$, pretreated with FZKA $(0,1$ and $2 \mathrm{mg} / \mathrm{ml})$ for $24 \mathrm{~h}$ at $37^{\circ} \mathrm{C}$, and a $200 \mu \mathrm{l}$ cell suspension was added into the upper chamber. The Transwell plate was then incubated at $37^{\circ} \mathrm{C}$ in a $5 \% \mathrm{CO}_{2}$ atmosphere for $16 \mathrm{~h}$. Non-migrated cells were removed with a cotton swab, and invaded cells were fixed in $4 \%$ paraformaldehyde for $15 \mathrm{~min}$ at room temperature prior to staining with crystal violet. Images were captured under x100 magnification with a fluorescence microscope (Olympus DP72; Olympus Corporation). Subsequently, $200 \mu 133 \%$ acetic acid was added to the chamber and the eluent was removed into 96-well plates. Absorbance at $570 \mathrm{~nm}$ was determined using an ELISA reader (Victor X5; Perkin Elmer, Inc., Waltham, MA, USA). The experiment was repeated at least three times.

MMP9 activity assay. The activity of MMP9 was measured using the SensoLyte ${ }^{\circledR} 520$ MMP9 assay kit (AnaSpec, Fremont, CA, USA) according to the manufacturer's protocol. The cells were seeded in 6-well plates at a density of $3 \times 10^{5}$ cells/well and treated with FZKA $(0,1,2$ and $3 \mathrm{mg} / \mathrm{ml})$ for $24 \mathrm{~h}$. Subsequently, the cell culture media supernatant was collected and centrifuged at $1,000 \mathrm{x} \mathrm{g}$ for $15 \mathrm{~min}$ at $4^{\circ} \mathrm{C}$. The MMP containing samples were incubated with APMA (component $\mathrm{C}$ ) at a final concentration of $1 \mathrm{mM}$ in the assay buffer (Component D) and were incubated for $2 \mathrm{~h}$ at $37^{\circ} \mathrm{C}$ in order to activate pro-MMPs. The working solutions were then prepared by diluting the MMP9 substrate 1:100 in assay buffer. The reagents: $50 \mu 1$ MMP9 containing sample and $50 \mu 1$ MMP9 substrate solution, were mixed in a 96-well plate by gentle agitation for $30 \mathrm{sec}$. The reactions were incubated at $37^{\circ} \mathrm{C}$ for $1 \mathrm{~h}$ and fluorescence intensity was measured at excitation/emission $=490 / 520 \mathrm{~nm}$. The experiment was repeated three times.

Western blot analysis. Cells were seeded in 6-well plates at a density of $3 \times 10^{5}$ cells/well. Following $24 \mathrm{~h}$ of culture, cells were treated with FZKA $(0,1,1.5$ and $2 \mathrm{mg} / \mathrm{ml})$ and were incubated at $37^{\circ} \mathrm{C}$ for $24 \mathrm{~h}$. Then, the cells were harvested, washed and lysed with $1 \mathrm{X}$ radioimmunoprecipitation assay buffer (cat. no. 9806; CST Biological Reagents Company Limited, Shanghai, China). Protein concentration was determined using the bicinchoninic acid protein assay kit (Thermo Fisher Scientific, Inc.). Equal amounts of protein $(40 \mu \mathrm{g})$ from cell lysates were solubilized in 5X SDS sample buffer and were separated by $10 \%$ SDS-PAGE, prior to being transferred onto polyvinylidene fluoride membranes. Membranes were blocked with 5\% non-fat milk in TBS containing 1\% Tween-20 and were then incubated with primary antibodies against STAT3 (cat. no. 8232; CST Biological Reagents Company Limited; dilution, 1:1,000), p-STAT3 (cat. no. 4093; CST Biological Reagents Company Limited; dilution, 1:1,000), vimentin (cat. no. 12826; CST Biological Reagents Company Limited; dilution, 1:1,000), N-cadherin (cat. no. 13116; CST Biological Reagents Company Limited; dilution, 1:1,000), MMP9 (cat. no. 13667; CST Biological Reagents Company Limited; dilution, 1:1,000) and GAPDH (cat. no. 5174; CST Biological Reagents Company Limited; dilution, 1:3,000) at $4^{\circ} \mathrm{C}$ overnight. Subsequently, the membranes were washed and incubated with a secondary antibody against rabbit immunoglobulin G (cat. no. 1706515; Bio-Rad Laboratories, Inc., Hercules, CA, USA; dilution, 1:10,000) for $1 \mathrm{~h}$ at room temperature. The membranes were then washed and visualized using enhanced chemiluminescence solution (Merck KGaA, Darmstadt, Germany); the blots were exposed and scanned under the Bio-Rad ChemiDoc XRS+ Chemiluminescence imaging system (Bio-Rad Laboratories, Inc.). The results were analyzed using ImageJ software (version 1.48; National Institutes of Health).

Transient transfection assay. The cells were seeded in 6 -well plates $\left(3 \times 10^{5}\right.$ cells/well) and were allowed to reach 50-60\% confluence. The pCMV6-AC and pCMV6-AC-STAT3 vectors were obtained from OriGene Technologies, Inc. In each well, $2 \mu$ g pCMV6-AC control or pCMV6-AC-STAT3 constructs were transfected into the cells using Lipofectamine 3000 reagent for $30 \mathrm{~h}$ at $37^{\circ} \mathrm{C}$, according to the manufacturer's protocol. Subsequently, the cells were treated with $2 \mathrm{mg} / \mathrm{ml}$ FZKA for an additional $24 \mathrm{~h}$ prior to experimentation.

Statistical analysis. Statistical analysis was performed using SPSS 19.0 statistical software (SPSS, Inc., Chicago, IL, USA). All data are presented as the mean \pm standard deviation. Differences between groups were assessed by one-way analysis of variance and a Tukey's post hoc test was used for multiple comparisons. $\mathrm{P}<0.05$ was considered to indicate a statistically significant difference.

\section{Results}

Lung cancer cell growth is suppressed by FZKA. The present study detected the effects of FZKA on lung cancer cell growth. A cell viability assay was performed using trypan blue staining following treatment of lung cancer cells (H1650, A549 and PC9) with various doses of FZKA for $24 \mathrm{~h}$. The results demonstrated that FZKA significantly suppressed the growth of lung cancer cells (>50\% following $3 \mathrm{mg} / \mathrm{ml}$ FZKA treatment) in a dose-dependent manner (Fig. 1).

FZKA inhibits migration of lung cancer cells in vitro. A characteristic of tumor metastasis is the increased migratory ability of tumor cells. The present study conducted a wound-healing assay to determine the effects of FZKA on lung cancer cell migration. As presented in Fig. 2A, the scratch length of all three lung cancer cells was markedly extended by FZKA treatment in a dose-dependent manner, indicating the inhibitory effects of FZKA on lung cancer cell migration. To further verify the inhibitory effects of FZKA on lung cancer cell migration, a Transwell migration assay was used. The results confirmed that FZKA inhibited the migration of lung cancer cells in a dose-dependent manner (Fig. $2 \mathrm{~B} ; \sim 50 \%$ decrease in migration following treatment with $2 \mathrm{mg} / \mathrm{ml} \mathrm{FZKA).} \mathrm{These}$ results suggested that FZKA decoction inhibited lung cancer cell migration.

FZKA inhibits lung cancer cell invasion in vitro. Since treatment with FZKA was able to reduce the migratory capabilities of lung cancer cells, the present study aimed to determine the effects of FZKA on lung cancer cell invasion using a Transwell 
A

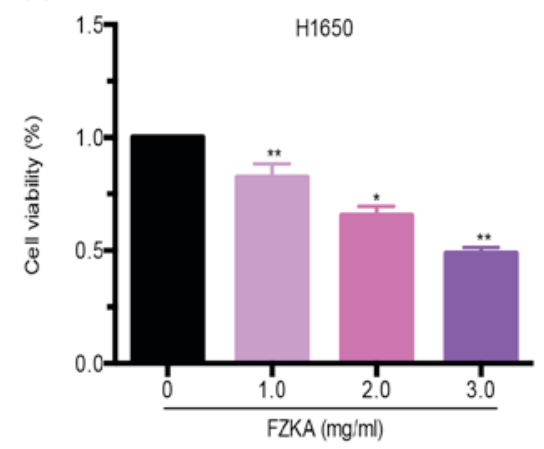

B

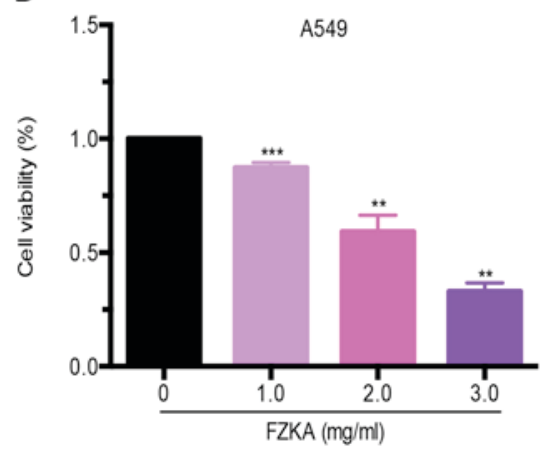

C

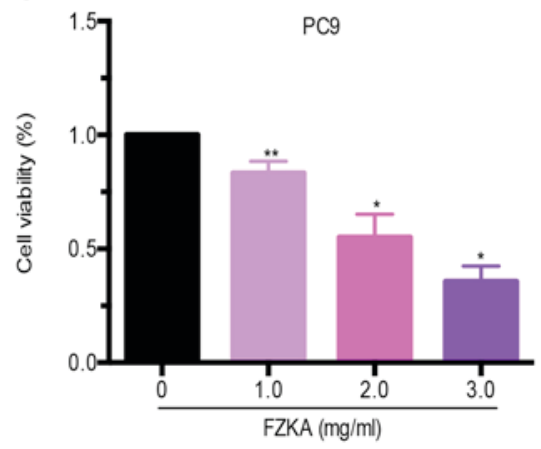

Figure 1. FZKA inhibits lung cancer cell growth. (A) H1650, (B) A549 and (C) PC9 cells were seeded into 6-well plates and treated with FZKA (0, 1, 2 and $3 \mathrm{mg} / \mathrm{ml})$. Cells were stained with trypan blue after $24 \mathrm{~h}$ and were counted using an automated cell counter. Data are presented as the mean \pm standard deviation of three independent experiments. ${ }^{*} \mathrm{P}<0.05,{ }^{* *} \mathrm{P}<0.01$ and ${ }^{* * *} \mathrm{P}<0.001$ vs. control (0 FZKA mg/ml). FZKA, Fuzheng Kang-Ai.
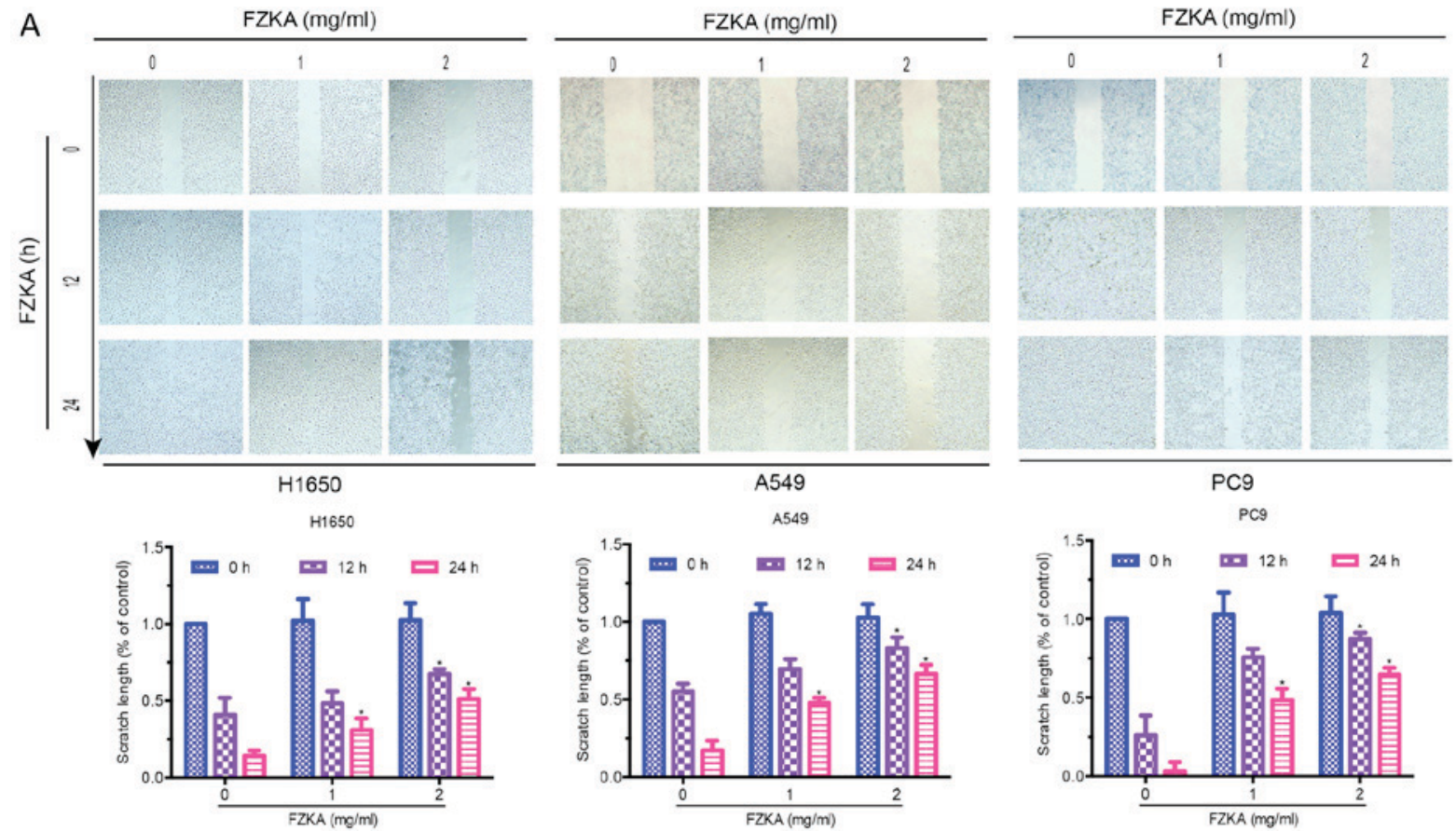

B
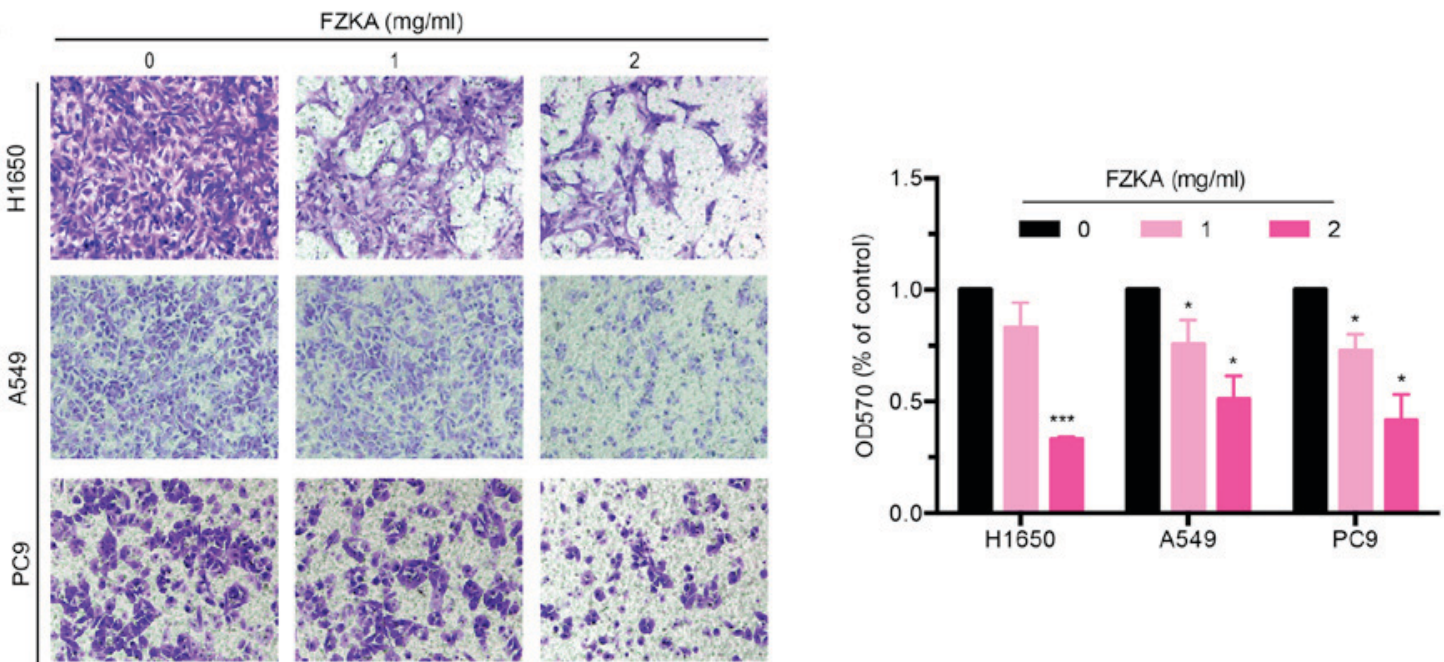

Figure 2. FZKA inhibits lung cancer cell migration. (A) H1650, A549 and PC9 cells were cultured (4x10 $)$ in 6-well plates, and were incubated until cell density reached $90 \%$. Cell monolayers were wounded by scratching with a $200-\mu 1$ pipette tip and were treated with FZKA (0, 1 and 2 mg/ml). Results are representative of three independent experiments. (B) H1650, A549 and PC 9 cells were plated in a Transwell plate. The lower chamber was filled with $500 \mu 1$ cell culture medium containing $30 \%$ fetal bovine serum. Cells were diluted to $0.5 \times 10^{6} / \mathrm{ml}$ and were pretreated with FZKA $(0,1$ and 2 mg/ml), after which a $200 \mu \mathrm{l}$ cell suspension was added to the upper chamber and was incubated for $16 \mathrm{~h}$. Magnification, $\mathrm{x} 40$. ${ }^{*} \mathrm{P}<0.05$ and ${ }^{* * * *} \mathrm{P}<0.001 \mathrm{vs}$. control $(0 \mathrm{FZKA} \mathrm{mg/ml)}$. FZKA, Fuzheng Kang-Ai; OD, optical density. 


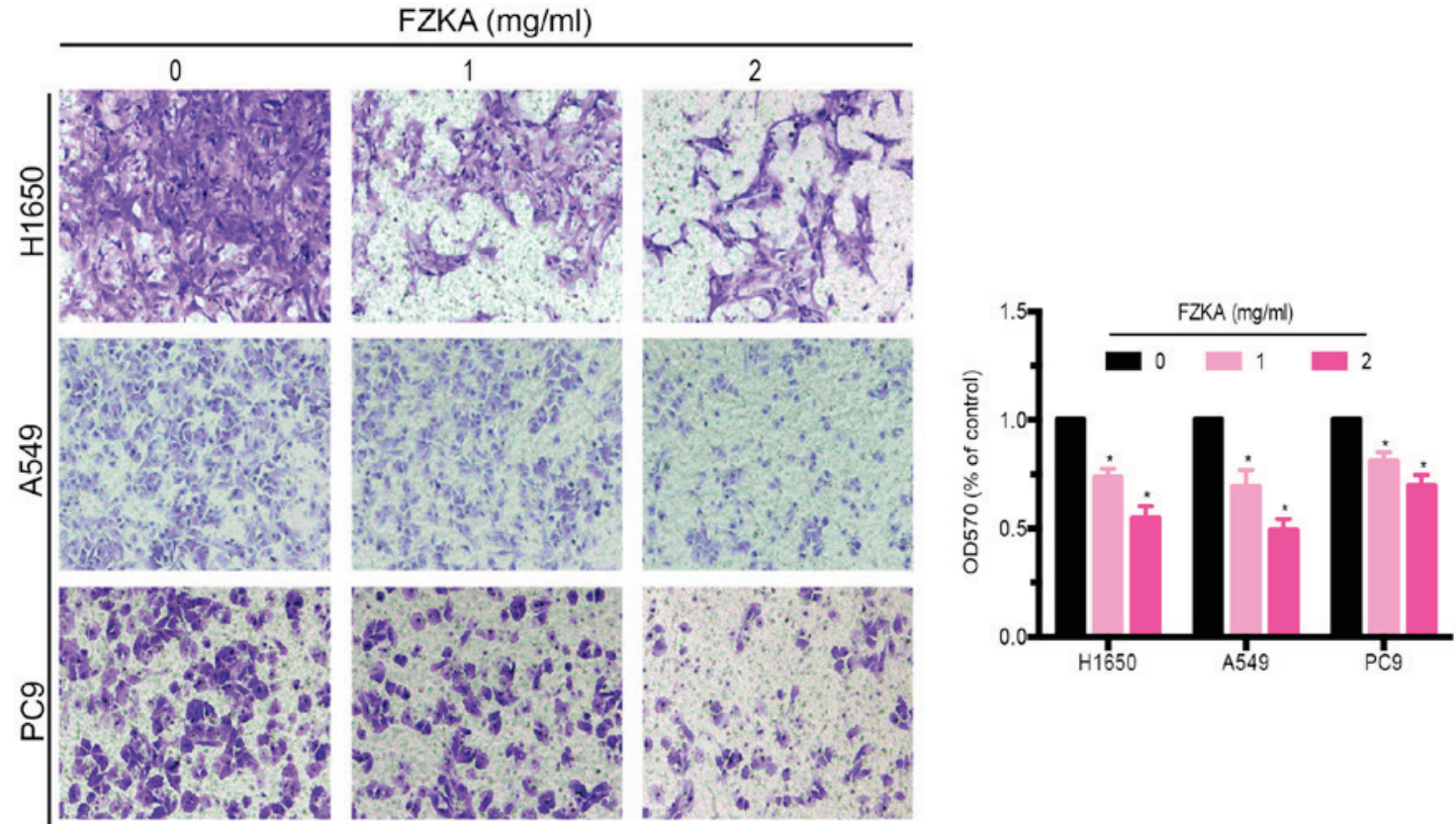

Figure 3. FZKA inhibits lung cancer cell invasion. H1650, A549 and PC9 cells were plated in a Transwell plate. Matrigel was injected into the upper chamber and $500 \mu \mathrm{l}$ cell culture medium with $30 \%$ fetal bovine serum was added to the lower chamber. Cells were diluted to $0.5 \times 10^{6} / \mathrm{ml}$ and were pretreated with FZKA $(0,1$ and $2 \mathrm{mg} / \mathrm{ml})$, after which a $200 \mu \mathrm{l}$ cell suspension was added to the upper chamber and was incubated for $16 \mathrm{~h}$. Absorbance was measured at $570 \mathrm{~nm}$ using a microplate reader. The experiment was repeated three times. Magnification, $\mathrm{x} 40 .{ }^{*} \mathrm{P}<0.05$ vs. control ( 0 FZKA mg/ml). FZKA, Fuzheng Kang-Ai; OD, optical density.

A
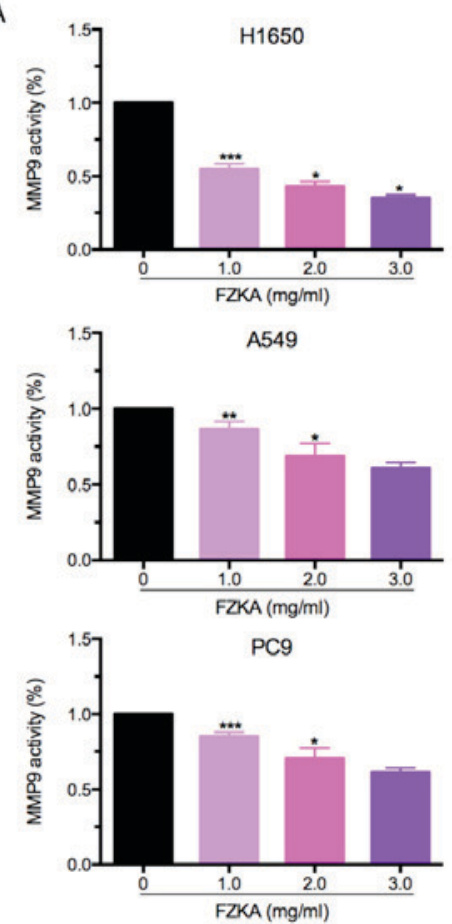

B

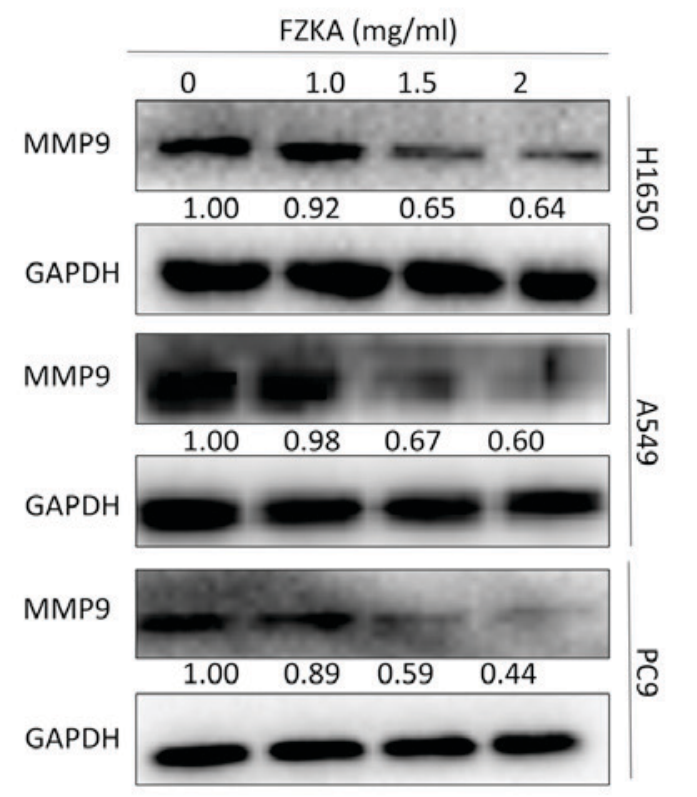

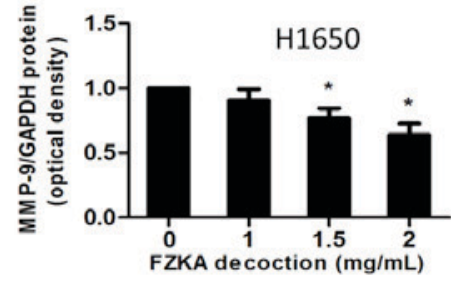
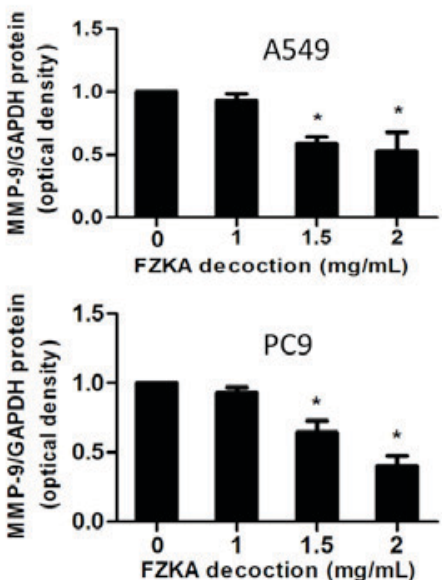

Figure 4. MMP9 is downregulated by FZKA treatment. (A) H1650, A549 and PC9 cells were seeded into 6-well plates and treated with FZKA (0, 1, 2 and $3 \mathrm{mg} / \mathrm{ml}$ ) for $24 \mathrm{~h}$. The reactions were measured by fluorescence intensity at excitation/emission=490/520 nm. Data are presented as the mean \pm standard deviation of three independent experiments. (B) Protein expression levels of MMP9 were decreased following FZKA treatment $(0,1,1.5 \mathrm{and} 2 \mathrm{mg} / \mathrm{ml})$ for $24 \mathrm{~h}$. Data were measured by ImageJ software. The experiment was repeated three times. ${ }^{*} \mathrm{P}<0.05,{ }^{* *} \mathrm{P}<0.01$ and ${ }^{* * * *} \mathrm{P}<0.001 \mathrm{vs}$. control ( 0 FZKA mg/ml). FZKA, Fuzheng Kang-Ai; MMP9, matrix metalloproteinase 9.

invasion assay. The results demonstrated that FZKA was also able to inhibit the invasion of the three lung cancer cell lines in a dose-dependent manner (Fig. 3; 60\% decrease in invasion following treatment with $2 \mathrm{mg} / \mathrm{ml}$ FZKA). These findings indicated that FZKA may act as a suppressor of lung cancer cell invasion. 
A

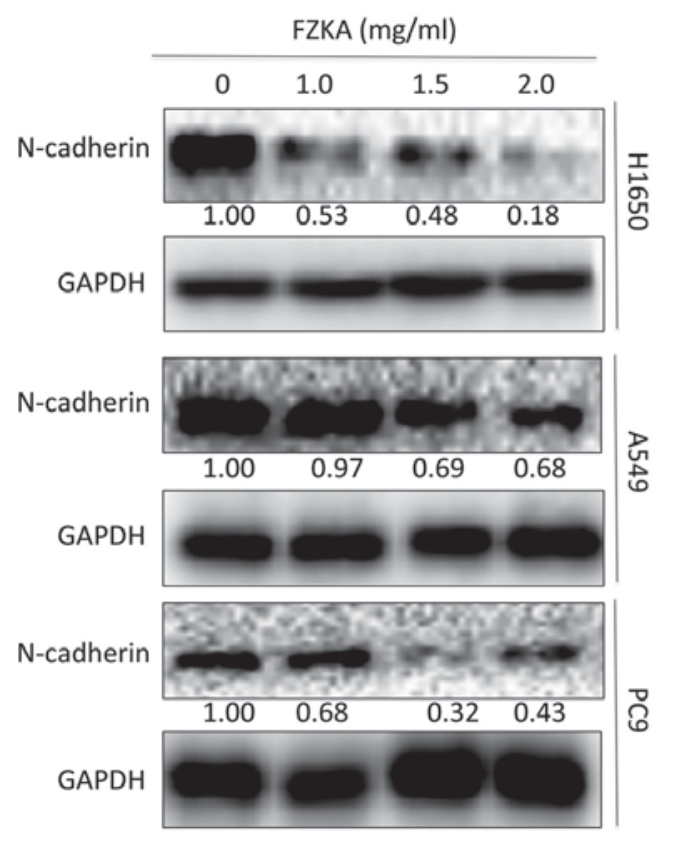

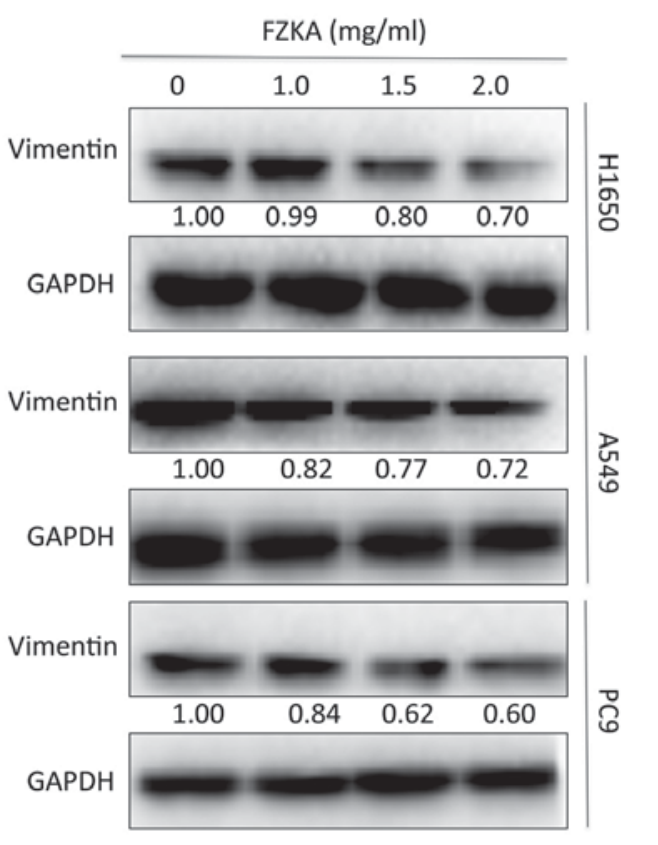

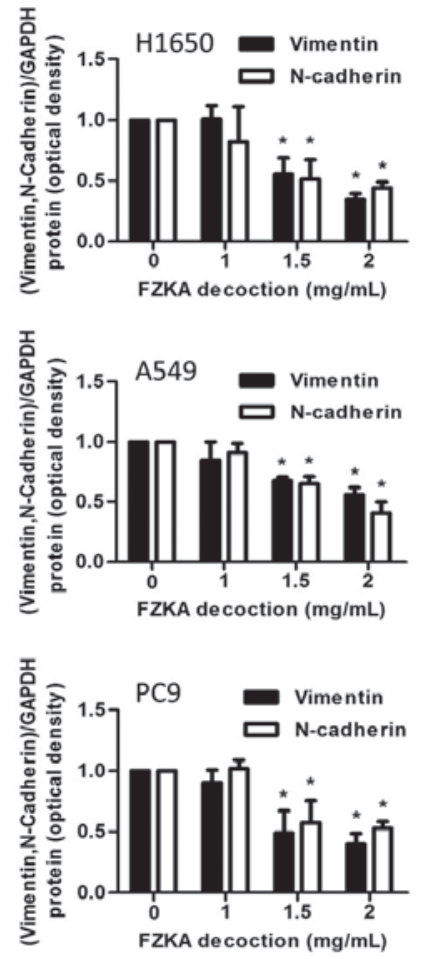

Figure 5. FZKA inhibits epithelial-mesenchymal transition in lung cancer cells. Protein expression levels of (A) N-cadherin and (B) vimentin were detected in lung cancer cells following treatment with FZKA by western blotting. Data were measured by ImageJ software. The experiment was repeated three times. ${ }^{*} \mathrm{P}<0.05$ vs. control (0 FZKA mg/ml). FZKA, Fuzheng Kang-Ai.

MMP9 activity and expression is downregulated by FZKA. MMP9 is a well-known factor that facilitates cell invasion; therefore, the present study detected MMP9 activity following FZKA treatment using an MMP9 activity assay. The results indicated that MMP9 activity was markedly downregulated by FZKA in a dose-dependent manner in all three lung cancer cell lines (Fig. 4A). Furthermore, the protein expression levels of MMP9 were decreased in the lung cancer cells following FZKA treatment in a dose-dependent manner (Fig. 4B). These data suggested that MMP9 served an important role in FZKA-mediated inhibition of lung cancer cell invasion.

EMT is involved in FZKA-induced inhibition of lung cancer cell metastasis. Previous studies have reported that metastasis and invasion are associated with EMT $(21,22)$. To determine if EMT also mediates the effects of FZKA on lung cancer cells, the present study detected the expression levels of proteins involved in the EMT process following FZKA treatment. The results indicated that the mesenchymal marker $\mathrm{N}$-cadherin and the intermediate filament protein vimentin, which are associated with increased cell motility (23), were downregulated by FZKA treatment in a dose-dependent manner (Fig. 5A and B). These data provided another potential mechanism by which FZKA affected lung cancer metastasis.

STAT3 may mediate the effects of FZKA on lung cancer cell metastasis. STAT3 is an oncogenic transcription factor, which leads to cell proliferation and invasion. Its activation can induce tumor cell growth, invasion and mesenchymal transition (24). In addition, MMP9 has been reported to be a target of STAT3 (25). In the present study, STAT3 activation was inhibited in a time-dependent manner in lung cancer cells following treatment with FZKA (Fig. 6A). Furthermore, overexpression of STAT3 was able to suppress the FZKA-mediated inhibition of MMP9 activity (Fig. 6B and C), indicating that STAT3 may be an upstream factor of MMP9, which is affected by FZKA treatment in lung cancer cells.

\section{Discussion}

Although advances have been made in the treatment of human cancers, cancer remains a leading cause of human mortality each year. More effective therapies are therefore required for the treatment of patients with cancer. Traditional Chinese medicine popular in Chinese and East Asian societies and serves an active role in modern healthcare systems, including in the treatment of patients with cancer, and therefore may be considered a potential effective strategy for the treatment of human cancers.

The present study was based on our previous clinical and fundamental findings, which indicated that FZKA could sensitize the effects of gefitinib on patients with late stage lung cancer, and prolong the PFS and MST in patients with NSCLC (17-20). In addition, FZKA was reported to inhibit lung cancer cell growth in vivo and in vitro (17-20). The present study aimed to determine the role and mechanisms of FZKA decoction on the process of lung cancer cell metastasis. Initially, the inhibitory role of FZKA in lung cancer cell growth was identified. In addition, the results demonstrated that FZKA significantly inhibited lung cancer cell migration and invasion, as determined by wound-healing and Transwell 
A

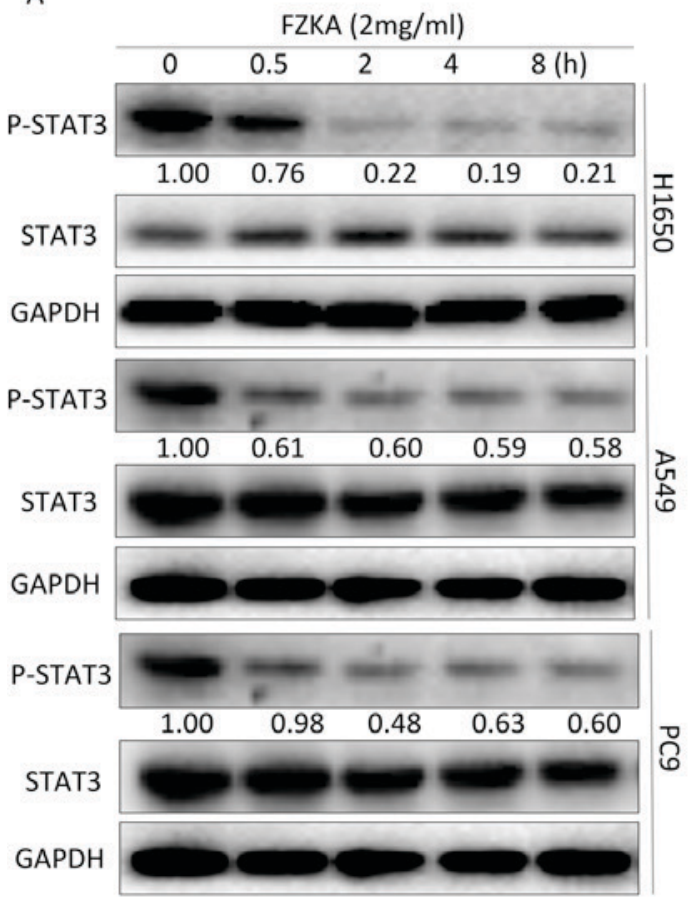

B
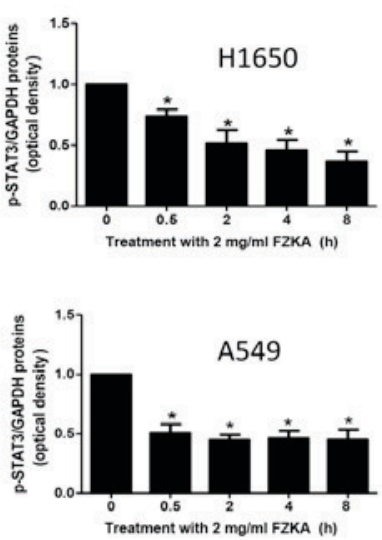

PCMV6-STAT3

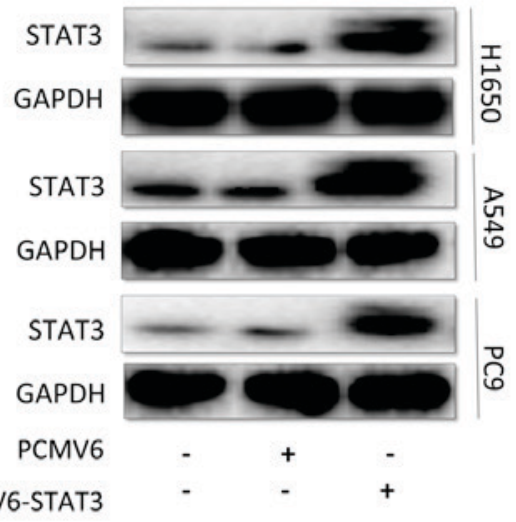

C

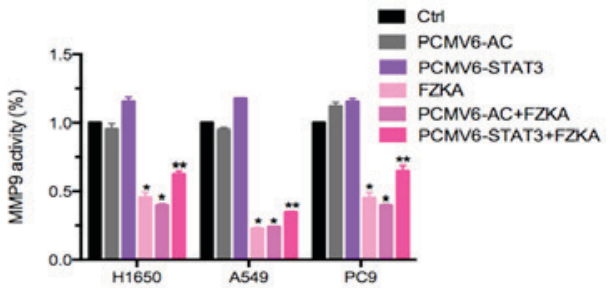

Figure 6. STAT3 regulates MMP9 activity in lung cancer cells treated with FZKA. (A) Protein expression levels of STAT3 were reduced following treatment with FZKA ( $2 \mathrm{mg} / \mathrm{ml} ; 0,0.5,2,4$ and $8 \mathrm{~h}$ ). "P<0.05 vs. 0 h. (B) To overexpress STAT3, cells (H1650, A549 and PC9) were seeded into 6-well plates, and transfected with pCMV6-AC (negative control) and pCMV6-AC-STAT3 DNA constructs, prior to treatment with FZKA. STAT3 protein expression was then measured by western blot analysis. (C) MMP9 activity was increased by STAT3 overexpression. Following treatment with FZKA, the FZKA-mediated inhibition of MMP9 activity was significantly suppressed by STAT3 overexpression. " $\mathrm{P}<0.05$ and ${ }^{* *} \mathrm{P}<0.01$ vs. control (Ctrl). FZKA, Fuzheng Kang-Ai; MMP9, matrix metalloproteinase 9; STAT5, signal transducer and activator of signaling 3; Ctrl, control.

assays. While the three lung cancer cell lines used in the present study responded to different extents to FZKA decoction, the overall effects of FZKA were consistent in all of the cell lines suggesting that the FZKA decoction had substantial inhibitory effects on human lung cancer cells.

MMP9, which is closely associated with the invasive and metastatic potential of numerous types of solid cancer (26), is critical during the process of FZKA-induced inhibition of lung cancer cell invasion. The present study demonstrated that MMP9 secretion was inhibited by FZKA treatment, as determined using an MMP9 activity assay. MMPs are able to degrade various components of the ECM and basement membrane (27). Once MMP9 is activated, it is able to degrade collagen in the ECM, which increases the metastasis of cancer cells (28). Therefore, the FZKA-induced inhibition of MM9 activity and expression may be considered an important mechanism by which FZKA inhibits lung cancer cell metastasis. Furthermore, STAT3 activation was inhibited by FZKA treatment. Notably, in cells overexpressing STAT3, as mediated by transient transfection, the FZKA-mediated inhibition of MMP9 activity was suppressed to some extent. Aberrant activation of STAT3 contributes to cancer progression in human malignances (29). Therefore, inhibition of STAT3 activation by FZKA may hinder tumor progression. Furthermore, the STAT3/MMP9 pathway has been demonstrated to participate in colon cancer cell invasion (30). The present study obtained similar results suggesting that the STAT3/MMP9 pathway may mediate the inhibitory effects of FZKA decoction on lung cancer cell metastasis.
The present study detected the expression levels of $\mathrm{N}$-cadherin and vimentin, two important proteins involved in the EMT process, both of which were downregulated by FZKA treatment. EMT is characterized by the loss of epithelial characteristics and the acquisition of mesenchymal characteristics. The induction of mesenchymal markers, including $\mathrm{N}$-cadherin and vimentin, are hallmark early- and late-stage events of EMT, respectively (31). The present study demonstrated that FZKA inhibited EMT, as indicated by a decrease in the protein expression levels of N-cadherin and vimentin. EMT is a well-known molecular mechanism associated with cancer metastasis (32). Therefore, FZKA-induced inhibition of EMT in lung cancer cells may be a potential mechanism underlying the effects of FZKA treatment on patients with lung cancer. Since EMT can also be induced by MMPs (33), the mesenchymal markers may be downstream proteins of the STAT3/MMP9 pathway. However, further study is required to verify this.

In conclusion, the present study identified a probable mechanism by which FZKA decoction inhibits lung cancer cell metastasis via the STAT3/MMP9 pathway, thus indicating that FZKA decoction may be considered as a potential effective strategy for the treatment of patients with lung cancer. Briefly, in the present study, FZKA decoction inhibited lung cancer cell migration and invasion in vitro. In addition, the results demonstrated that the STAT3/MMP9 pathway and EMT may mediate the inhibitory effects of FZKA on lung cancer metastasis. These findings provide valid experimental evidence for the clinical usage of FZKA decoction in treating patients with late stage lung cancer. 


\section{Acknowledgements}

This work was supported by a grant from the National Natural Science Foundation of China (grant nos. 81273965 and 81272614), the Canadian Terry Fox Run Foundation for Cancer Research (grant no. YN2014TF01), the Science and Technology Planning Project of Guangdong Province (grant nos. 2016A020226035 and 2014A020221024), and the Administration of Traditional Chinese Medicine of Guangdong Province in China (grant no. 20141104).

\section{References}

1. Siegel R, Ma J, Zou Z and Jemal A: Cancer statistics, 2014. CA Cancer J Clin 64: 9-29, 2014.

2. Jemal A, Siegel R, Xu J and Ward E: Cancer statistics, 2010. CA Cancer J Clin 60: 277-300, 2010.

3. Chen W, Zheng R, Zhang S, Zhao P, Li G, Wu L and He J: Report of incidence and mortality in China cancer registries, 2009. Chin J Cancer Res 25: 10-21, 2013.

4. Verdecchia A, Francisci S, Brenner H, Gatta G, Micheli A, Mangone L and Kunkler I; EUROCARE-4 Working Group: Recent cancer survival in Europe: A 2000-02 period analysis of EUROCARE-4 data. Lancet Oncol 8: 784-796, 2007.

5. Thomas G: Furin at the cutting edge: From protein traffic to embryogenesis and disease. Nat Rev Mol Cell Biol 3: 753-766, 2002.

6. Fidler IJ: The pathogenesis of cancer metastasis: The 'seed and soil' hypothesis revisited. Nat Rev Cancer 3: 453-458, 2003.

7. Rhee JS and Coussens LM: RECKing MMP function: Implications for cancer development. Trends Cell Biol 12: 209-211, 2002

8. Wang R, Ke ZF, Wang F, Zhang WH, Wang YF, Li SH and Wang LT: GOLPH3 overexpression is closely correlated with poor prognosis in human non-small cell lung cancer and mediates its metastasis through upregulating MMP-2 and MMP-9. Cell Physiol Biochem 35: 969-982, 2015.

9. Ahmad R, Shihab PK, Jasem S and Behbehani K: FSL-1 induces MMP-9 production through TLR-2 and NF- $\kappa \mathrm{B} / \mathrm{AP}-1$ signaling pathways in monocytic THP-1 cells. Cell Physiol Biochem 34: 929-942, 2014

10. Yang CQ, Li W, Li SQ, Li J, Li YW, Kong SX, Liu RM, Wang SM and Lv WM: MCP-1 stimulates MMP-9 expression via ERK 1/2 and p38 MAPK signaling pathways in human aortic smooth muscle cells. Cell Physiol Biochem 34: 266-276, 2014.

11. Cheng X, Yang Y, Fan Z, Yu L, Bai H, Zhou B, Wu X, Xu H, Fang M, Shen A, et al: MKL1 potentiates lung cancer cell migration and invasion by epigenetically activating MMP9 transcription. Oncogene 34: 5570-5581, 2015.

12. Sreekumar R, Sayan BS, Mirnezami AH and Sayan AE: MicroRNA control of invasion and metastasis pathways. Front Genet 2: 58, 2011.

13. Xia $\mathrm{H}$ and Hui KM: MicroRNAs involved in regulating epithelial-mesenchymal transition and cancer stem cells as molecular targets for cancer therapeutics. Cancer Gene Ther 19: 723-730, 2012.

14. Bromberg JF, Wrzeszczynska MH, Devgan G, Zhao Y, Pestell RG, Albanese C and Darnell JE Jr: Stat3 as an oncogene. Cell 98: 295-303, 1999.

15. Song L, Turkson J, Karras JG, Jove R and Haura EB: Activation of Stat 3 by receptor tyrosine kinases and cytokines regulates survival in human non-small cell carcinoma cells. Oncogene 22: 4150-4165, 2003.
16. Liu F, Zhang T, Zou S, Jiang B and Hua D: B7-H3 promotes cell migration and invasion through the Jak2/Stat3/MMP9 signaling pathway in colorectal cancer. Mol Med Rep 12: 5455-5460, 2015.

17. Yang XB, Wu WY, Long SQ, Deng H, Pan ZQ, He WF, Zhou YS, Liao GY, Li QP, Xiao SJ and Cai JZ: Fuzheng Kang'ai decoction combined with gefitinib in advanced non-small cell lung cancer patients with epidermal growth factor receptor mutations: Study protocol for a randomized controlled trial. Trials 16: 146, 2015.

18. Wu WY, Yang XB, Deng H, Long SQ, Sun LS, He WF, Zhou YS Liao GY, Chan SM and Shan SP: Treatment of advanced non-small cell lung cancer with extracorporeal high frequency thermotherapy combined with Chinese medicine. Chin J Integr Med 16: 406-410, 2010.

19. Yang XB, Wu WY, Long SQ, Deng $H$ and Pan ZQ: Effect of gefitinib plus Chinese herbal medicine (CHM) in patients with advanced non-small-cell lung cancer: A retrospective case-control study. Complement Ther Med 22: 1010-1018, 2014.

20. Zheng F, Wu J, Li X, Tang Q, Yang L, Yang X, Wu W and Hann SS: Chinese Herbal Medicine Fuzheng Kang-Ai Decoction inhibited lung cancer cell growth through AMPK $\alpha$-mediated induction and interplay of IGFBP1 and FOXO3a. Evid Based Complement Alternat Med 2016: 5060757, 2016.

21. Iwatsuki M, Mimori K, Yokobori T, Ishi H, Beppu T, Nakamori S, Baba $\mathrm{H}$ and Mori M: Epithelial-mesenchymal transition in cancer development and its clinical significance. Cancer Sci 101: 293-299, 2010.

22. Wan L, Pantel K and Kang Y: Tumor metastasis: Moving new biological insights into the clinic. Nat Med 19: 1450-1464, 2013.

23. Lee JM, Dedhar S, Kalluri R and Thompson EW: The epithelial-mesenchymal transition: New insights in signaling, development and disease. J Cell Biol 172: 973-981, 2006.

24. Lui VW, Wong EY, Ho Y, Hong B, Wong SC, Tao Q, Choi GC, $\mathrm{Au}$ TC, Ho K, Yau DM, et al: STAT3 activation contributes directly to Epstein-Barr virus-mediated invasiveness of nasopharyngeal cancer cells in vitro. Int J Cancer 125: 1884-1893, 2009.

25. Guo K, Ma Q, Li J, Wang Z, Shan T, Li W, Xu Q and Xie K: Interaction of the sympathetic nerve with pancreatic cancer cells promotes perineural invasion through the activation of STAT3 signaling. Mol Cancer Ther 12: 264-273, 2013.

26. El-Badrawy MK, Yousef AM, Shaalan D and Elsamanoudy AZ: Matrix metalloproteinase-9 expression in lung cancer patients and its relation to serum mmp-9 activity, pathologic type, and prognosis. J Bronchology Interv Pulmonol 21: 327-334, 2014.

27. Vilen ST, Salo T, Sorsa T and Nyberg P: Fluctuating roles of matrix metalloproteinase-9 in oral squamous cell carcinoma. ScientificWorldJournal 2013: 920595, 2013.

28. Backstrom JR and Tökés ZA: The $84-\mathrm{kDa}$ form of human matrix metalloproteinase-9 degrades substance P and gelatin. J Neurochem 64: 1312-1318, 1995.

29. Yu H and Jove R: The STATs of cancer-new molecular targets come of age. Nat Rev Cancer 4: 97-105, 2004.

30. Ao N, Liu Y, Bian X, Feng H and Liu Y: Ubiquitin-specific peptidase 22 inhibits colon cancer cell invasion by suppressing the signal transducer and activator of transcription 3/matrix metalloproteinase 9 pathway. Mol Med Rep 12: 2107-2113, 2015.

31. Shirakihara T, Saitoh M and Miyazono K: Differential regulation of epithelial and mesenchymal markers by deltaEF1 proteins in epithelial mesenchymal transition induced by TGF-beta. Mol Biol Cell 18: 3533-3544, 2007.

32. Gupta GP and Massagué J: Cancer metastasis: Building a framework. Cell 127: 679-695, 2006

33. Orlichenko LS and Radisky DC: Matrix metalloproteinases stimulate epithelial-mesenchymal transition during tumor development. Clin Exp Metastasis 25: 593-600, 2008. 